\title{
Simulation of snow mass and extent in general circulation models
}

\author{
Zong-Liang Yang,,${ }^{1,2 *}$ Robert E. Dickinson, ${ }^{1,2}$ Andrea N. Hahmann, ${ }^{1}$ Guo-Yue Niu, ${ }^{3}$ \\ M. Shaikh, ${ }^{1}$ Xiaogang Gao, ${ }^{2}$ Roger C. Bales, ${ }^{2}$ Soroosh Sorooshian ${ }^{2}$ and Jiming Jin ${ }^{2}$ \\ ${ }^{1}$ Institute of Atmospheric Physics, University of Arizona, Tucson, AZ 85721, USA \\ ${ }^{2}$ Department of Hydrology and Water Resources, University of Arizona, Tucson, AZ 85721, USA \\ ${ }^{3}$ LAPC, Institute of Atmospheric Physics, CAS, Beijing, China 100029
}

\begin{abstract}
:
An evaluation of the Biosphere-Atmosphere Transfer Scheme (BATS) snow submodel was conducted, both in a stand-alone mode and within the National Center for Atmospheric Research (NCAR) Community Climate Model version 3 (CCM3). We evaluated, in the stand-alone mode, the performance of BATS parameterizations at local scales using ground-based observations from the former Soviet Union and from Mammoth Mountain, California. The BATS snow scheme reproduces well the seasonal evolution of snow water equivalent in both sites, and the results for the Mammoth Mountain site compare well with those from a more complex, physically based model (SNTHERM). In the coupled mode, we evaluated the modelled snow cover extent, snow mass, precipitation and temperature from BATS as linked to the NCAR CCM3 using available observations. The coupled models capture the broad pattern of seasonal and geographical distribution of snow cover, with better overall performance than the passive microwave snow data derived from the Nimbus-7 Scanning Multi-channel Microwave Radiometer (SMMR) which generally underestimates snow depth. In terms of continents, the snow mass is better simulated during the accumulation period than during the melt period, which is the case for both North America and Eurasia. The simulation of snow mass, precipitation and air temperature for North America is slightly better than that for Eurasia. A rigorous evaluation of snow simulations in coupled land-atmosphere models requires high quality global datasets of snow cover extent, snow depth and snow water equivalent. The available datasets and model outputs are not yet ready to fulfil this objective. Copyright (C) 1999 John Wiley \& Sons, Ltd.
\end{abstract}

KEY WORDS snow mass; snow extent; snow model; general circulation model (GCM); biosphere-atmosphere transfer scheme (BATS); global datasets \footnotetext{
AZ 85721, USA. E-mail: zly@breeze.atmo.arizona.edu

Contract grant sponsor: NASA EOS Interdisciplinary Scientific Research Program.

Contract grant number: U.P.N. 428-81-22.

Contract grant number: U.P.N. 429-81-22.

Contract grant sponsor: NASA.

Contract grant number: NAG8-1520.

Contract grant sponsor: NASA/EOS Interdisciplinary Research Program.

Contract grant number: NAG53640\#1.

Contract grant sponsor: EOS.

Contract grant number: NAGW-2062.
}

* Correspondence to: Dr Zong-Liang Yang, Institute of Atmospheric Physics, PAS Building \#81, The University of Arizona, Tucson, 


\section{INTRODUCTION}

Snow processes are an important component of a general circulation model (GCM) because of the unique snow characteristics, such as high albedo, low thermal conductivity, and considerable spatial and temporal variability. Compared to other surfaces, snow acts in a different manner in controlling energy and water exchanges with the atmosphere and the underlying soil. In addition, the timing of snowmelt and the subsequent fate of meltwater play an important role in the hydrological cycle.

Although detailed one-dimensional snow models exist (e.g., Anderson, 1976; Jordan, 1991), GCMs use relatively simple snow models for computational reasons (Dickinson, et al., 1981, 1986, 1993; Verseghy, 1991; Loth et al., 1993; Marshall et al., 1994; Lynch-Stieglitz, 1994). These GCM snow models, generally with one to five layers, are designed to resolve the diurnal and seasonal variations of surface processes such as surface temperature and heat fluxes, thereby simplifying the treatment of the internal snow processes (e.g., the retention and transport of meltwater, melting and freezing, diffusion of temperature and water vapour, and the extinction of solar radiation). Because GCMs are shown to be highly sensitive to snow processes (e.g., Yeh et al., 1983; Cess et al., 1991), it is critical to have a one-dimensional snow model with adequate realism, yet still be efficient for long-term climate integrations. One way to achieve this is through a three-tier approach. First, existing GCM snow models need to be tested in stand-alone mode against real data, or with detailed one-dimensional models. Second, point models must be extended to account for the heterogeneous nature in each of the GCM land grid boxes. For instance, one needs to consider how the snow patchiness and sub-grid scale variability of snow depth are determined by weather events, topography and vegetation. Third, the simulation of snow and related variables in existing GCM runs needs to be analyzed and compared with gridded observed datasets to establish model credibility. The second issue is not within the scope of this paper. Generally speaking, the off-line study aids in understanding the models' performance under an idealized and controlled framework because the changes of the snow state variables and fluxes do not feed back to the meteorological forcing variables. On the other hand, the coupled simulations provide an assessment of the snow model and the host GCM under a more realistic and dynamic framework because the simulated snow cover and forcing variables (in particular, precipitation and temperature) impact each other. These two lines of study are complementary, and are the subject of this paper.

This research focuses on one such snow model, the Biosphere-Atmosphere Transfer Scheme (BATS) (Dickinson et al., 1993). First, stand-alone tests of the model using long-term snow data for six midlatitude grassland stations in Russia and data from Mammoth Mountain, California, are presented. The latter site is characterized by a deep snowpack (up to three to five metres) during the melting season, and hence provides an extreme case for evaluating the performance of the BATS snow model. In the latter case, the BATS model is also compared with a more complex snow scheme. Results of the snow simulation from coupling BATS to a GCM are presented for two continents with significant snow covers: North America and Eurasia. The simulations are assessed with climatological datasets of snow, precipitation and screen level air temperature. Specifically, two research questions are addressed: (1) Is the BATS snow model adequately simulating surface snow processes? (2) Are the available global datasets and the model output variables adequate to assess the performance of the coupled land-atmosphere model?

\section{STAND-ALONE TEST OF THE BATS SNOW MODEL}

\section{Description of BATS snow model}

The BATS snow submodel (Dickinson et al., 1993) is designed for use in GCMs, for which the diurnal and seasonal time scales are most important. BATS snow temperature is calculated using a force-restore thermal model (Dickinson, 1988) whose main intent of layer design is to give correct diurnal temperature calculations for subfreezing snow and to couple to underlying soil for shallow snow. The BATS model computes a time-dependent snow depth, density and albedo for 15 vegetation types. The snow albedo is parameterized at both visible and near infrared wavelengths as a function of snow age, impurities, and solar zenith angle. The 
thermal conductivity is assumed to be a quadratic function of snow density. The fraction of the grid area covered by snow is parameterized to depend on snow depth and surface roughness for both vegetation and soil surfaces. The model neglects the extinction of solar radiation in the snowpack, and calculates the snowmelt from the surface energy balance. The meltwater is assumed to flow out of the snowpack immediately. Additional information on the snow portion of the BATS model can be found in Yang et al. (1997).

\section{Russian snow data}

Snow data are for six midlatitude grassland stations in Russia for the period 1978-83 as described by Robock et al. (1995) and Yang et al. (1997). Each station was located on a grass-covered plot. Meteorological forcing data (air temperature, dew point temperature, precipitation, wind speed, air pressure, low cloud cover fraction and total cloud cover fraction) for the period 1978-83 were measured regularly eight times per day (00:00, 03:00, 06:00, 09:00, 12:00, 15:00, 18:00, and 21:00) at the same time (Moscow legal time, Greenwich time plus three hours) for all six stations. The actinometric data (incoming solar radiation, net total radiation and surface albedo) were part of the regular measurements of the former Soviet Union actinometric station network. These measurements were taken six times per day at the mean local solar time (00:30, 06:30, 09:30, 12:30, 15:30, and 18:30). Tretyakov type gauges ( $2 \mathrm{~m}$ above ground level) were used to measure precipitation. Snow water equivalent (SWE) was independently measured along snow routes, transects of $1-2 \mathrm{~km}$ in the vicinity of these stations, on the 10th, 20th, and the last day of each month during the winter months, and was then averaged.

Yang et al. (1997) showed a detailed comparison of modelled and observed snow variables including snow depth, SWE, surface temperature and surface albedo. For the sake of reference as well as new insight into the model's performance, we showed a comparison of modelled against observed SWE (Figure 1). We employed a version of BATS in which the snow density and snow cover fraction formulation were modified to reproduce the observed snow depth and snow cover extent for the six sites ( $c f$. Yang et al., 1997). We used two sets of surface parameters, one as adopted in the GCM for the grassland, and the other adjusted to solely reproduce the observed soil moistures as described in Yang et al. (1998). The adjustment in vegetation parameters also affects the snow simulation. Table I lists the names of these parameters and their values. We also applied a wind correction to the winter precipitation measurements following Yang et al. (1997), and assumed the rain-snow transition temperature to be $0{ }^{\circ} \mathrm{C}$. The model was run to reach equilibrium with the given initial soil moisture. This was achieved by looping through the first year meteorological forcing data a number of times (typically ten years or less; see Yang et al., 1995), after which the whole six years' data were used to drive the model. Only the results from the last six years were analyzed.

As shown in Figure 1, the model is able to reproduce the timing of accumulation, length of snow covered period, and year-to-year variability, but does not reproduce the peak SWE well. Comparing our Figure 1 with Figure 1 in Yang et al. (1997), reveals that overestimation of the peak SWE coincides with positive

Table I. List of BATS vegetation parameters applicable to six stations. The soil type index varies from 1 (sand) to 12 (clay) (Dickinson et al., 1993). The table only lists the vegetation parameters that directly affect snow simulations. The parameter values are as used in BATS-CCM3 and the adjusted values are given in parentheses. $z_{0 c}$ is canopy roughness length (m) and $A_{v \max }$ is maximum value of vegetation cover fraction

\begin{tabular}{lcccc}
\hline Station & Vegetation type & Soil type index & $z_{0 c}$ & $A_{v \max }$ \\
\hline Yershov & Short grass & 6 & $0 \cdot 05(0 \cdot 10)$ & $0 \cdot 80(0 \cdot 90)$ \\
Tulun & Short grass & 8 & $0 \cdot 05(0 \cdot 20)$ & $0 \cdot 80(0 \cdot 95)$ \\
Uralsk & Short grass & 2 & $0 \cdot 05(0 \cdot 10)$ & $0 \cdot 80(0 \cdot 90)$ \\
Kostroma & Short grass & 12 & $0 \cdot 05(0 \cdot 15)$ & $0 \cdot 80(0 \cdot 95)$ \\
Khabarovsk & Short grass & 12 & $0 \cdot 05(0 \cdot 20)$ & $0 \cdot 80(0 \cdot 90)$ \\
Ogurtsovo & Short grass & 7 & $0 \cdot 05(0 \cdot 10)$ & $0 \cdot 80(0 \cdot 90)$ \\
\hline
\end{tabular}




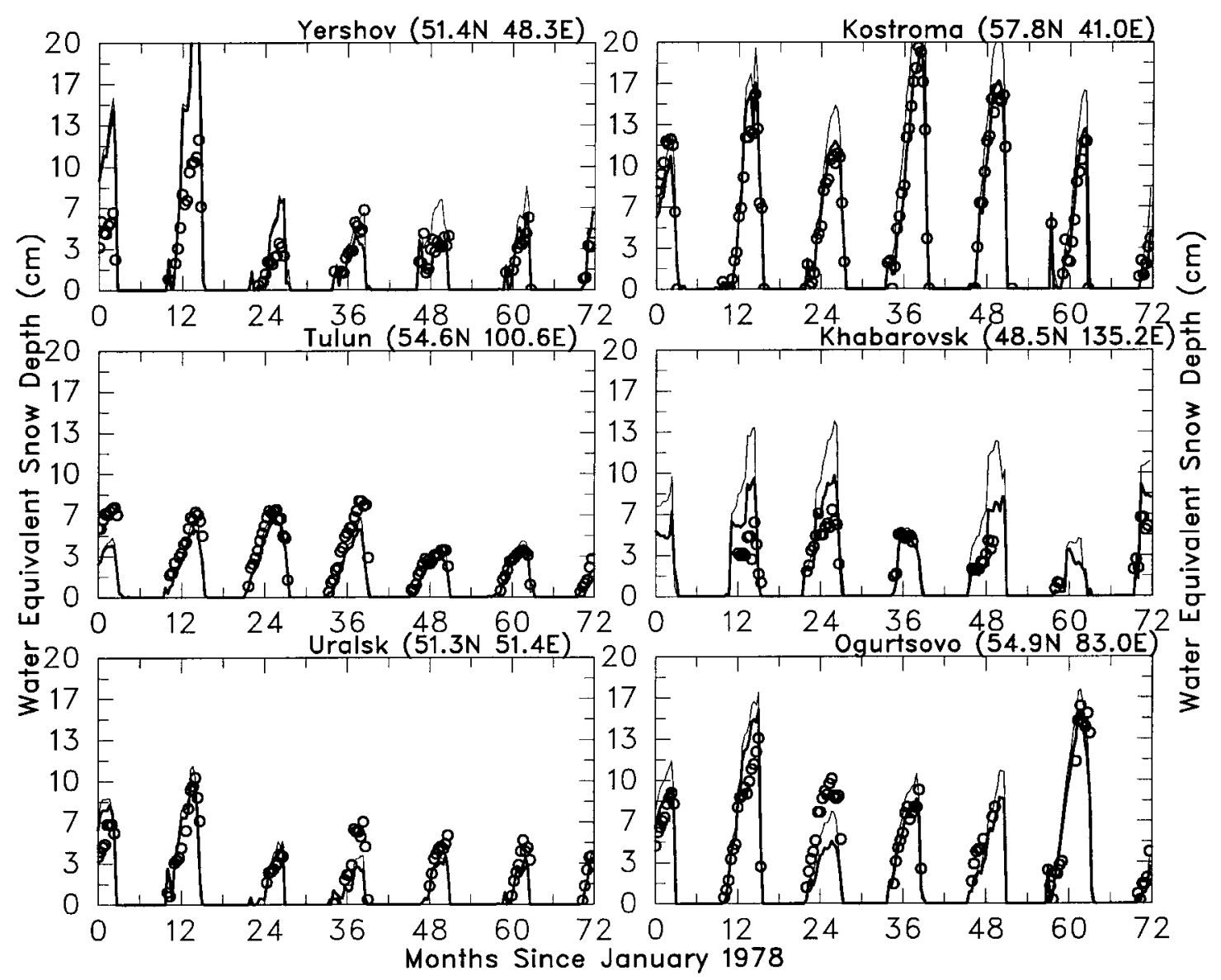

Figure 1. Simulations and observations of snow mass in $\mathrm{cm}$ water for the six stations for the entire six years. The SWE measurements (shown by circles) were made along snow courses in the vicinity of the stations every ten days during the winter. Because the sites were located in flat grassland, the snow measurements were representative of a region (see Yang et al., 1997). The simulations (shown by solid lines) are for two runs, one with default parameters (thin lines) and the other with modified parameters (thick lines). The abscissa labels indicate the beginning of the months for the period 1978-83

biases in the snow depth measurements from the permanent stakes and from the snow courses. This suggests that there existed some blowing snow events during which the forcing data collected at a station did not have a good representation of the snowfall along the snow courses. The results appear to show the model has better simulations during the accumulation period than during the melt period. However, this is due to the fact that the melt process is so rapid that the ten-day measurement interval is not adequate to resolve it.

There are some disagreements in the simulations with both GCM-type of parameters and adjusted parameters. For Khabarovsk, the modified parameters lead to much better simulations than do the default parameters, because the larger vegetation cover and roughness, on one hand, result in a smaller vegetated area that is covered by snow, thereby leading to more absorbed solar radiation for melting snow; on the other hand, they enhance the sublimation rate, which in turn reduces the thickness of the snowpack. Overall, these results demonstrate that for midlatitude shallow snowpack, the simple snow model, as used in BATS, which neglects the retention of liquid water, can perform reasonably well. 


\section{Mammoth Mountain snow data}

Automatic snow and meteorological measurements have been made at Mammoth Mountain in the eastern Sierra Nevada, California since 1987 (Harrington and Bales, 1998). Lysimeter and pit data are taken from two sites (north and south) which are about $20 \mathrm{~m}$ apart and have different snow depths. The meteorological measurements include air temperature, relative humidity, wind speed, and net solar and downward long-wave radiation at 15 -minute intervals. Figure 2 shows the daily mean values of these variables during the melt season of 1993. Biweekly, two snow pits excavated from the sites provide SWE and other snow variables.

The Mammoth Mountain site is characterized by deep snow that can be up to three to five metres in physical depth and a long melting season that extends into June. From a climate viewpoint, the most crucial time for snow modelling is that of the spring melt period. Over this period, solar fluxes are large and therefore albedo variations have a major effect - at the same time the snow removal can drastically change surface albedos; furthermore, the timing of the snowmelt is a major factor on the timing of water removal by runoff. The spring melt period has other unique features, in particular, the occurrence of meltwater which can either be removed from the snowpack and then infiltrated into the soil and/or generate runoff or can refreeze in the snowpack.

Jin et al. (1999) have provided detailed documentation of the processes involved in melting, such as penetration of solar radiation, daytime melting, nighttime freezing, heat conduction and transport due to vapour, water and ice, and profiles of temperature and density. Their study was formulated both from a modelling and an observational point of view. On the other hand, our research focuses on surface boundary layer stability, surface heat fluxes and their role in controlling melt. We used snow measurements from two adjacent sites (north and south), both having the same meteorological forcing variables (Figure 2). During this melt period, from day of year (DOY) 109 to 172, the surface atmospheric boundary layer is predominantly stable (Figure 3 ), with bulk Richardson numbers $\left(R_{b}\right)$ between 0 and 0.1 occurring $57 \%$ of the time. In fact, the frequency of $R_{b}$ at $(0,0.05),(0.05,0.075)$ and $(0.075,0.1)$ is 46,6 and $5 \%$, respectively, indicating the $(0,0.05)$ interval has the most dominant frequency. Analysis of a subset of the data between DOY 123-132 shows a remarkably similar pattern, in which $0<R_{b}<0 \cdot 1$ appeared in $58 \%$ of that period. Jordan (1992) indicated the importance of a proper formulation of the drag coefficient $\left(C_{D}\right)$ in modelling the snowmelt. This dataset serves as a good test bed to examine the performance of $C_{D}$ that is used in BATS and SNTHERM.

Figure 4(a) illustrates the evolution of the modelled snow water equivalent from BATS using the default $C_{D}$ formula that is the same as those used in the National Center for Atmospheric Research (NCAR) Community Climate Model version 2 (CCM2) (Hack et al., 1993; Holtslag and Boville, 1993) or CCM3 (Kiehl et al., 1996), except that during unstable conditions the BATS $C_{D}$ is the average of those for momentum and heat in CCM2 (or CCM3) and that the off-line run uses different values of von Karman constant and snow roughness length as discussed later. Also shown in Figure 4(a) are the simulations from BATS using $C_{D}$ taken from the February 1997 version of the SNTHERM code. The SNTHERM drag formulations are described in Jordan (1992). We assess the model performance by comparing with the observed SWE.

Figure 4 shows that BATS simulates the ablation process well, and that a considerably better performance results from using SNTHERM $C_{D}$. The SNTHERM formulation enhances the sublimation and the sensible heat flux, both shown here as accumulated values in metres of water. The enhanced sensible heat enters the snowpack and accelerates the melting rate. Questions arise as to why the SNTHERM $C_{D}$ leads to improved simulations of SWE. Because stable conditions prevail in the surface boundary layer, and $0<R_{b}<0.05$ has a dominant frequency (46\%), one would expect the major difference in the fluxes from the two simulations to be attributed to the differences in $C_{D}$ values for $0<R_{b}<0.05$. Figure 5 shows a comparison between the formulations used in BATS and SNTHERM as a function of $R_{b}$. Indeed, the SNTHERM $C_{D}$ is greater than the BATS $C_{D}$ for $0<R_{b}<0 \cdot 05$. Two reasons are found to be responsible for this. First, in the off-line run, BATS assigns the von Karman constant to be $0 \cdot 378$, while SNTHERM uses 0.4. Second, in computing the 

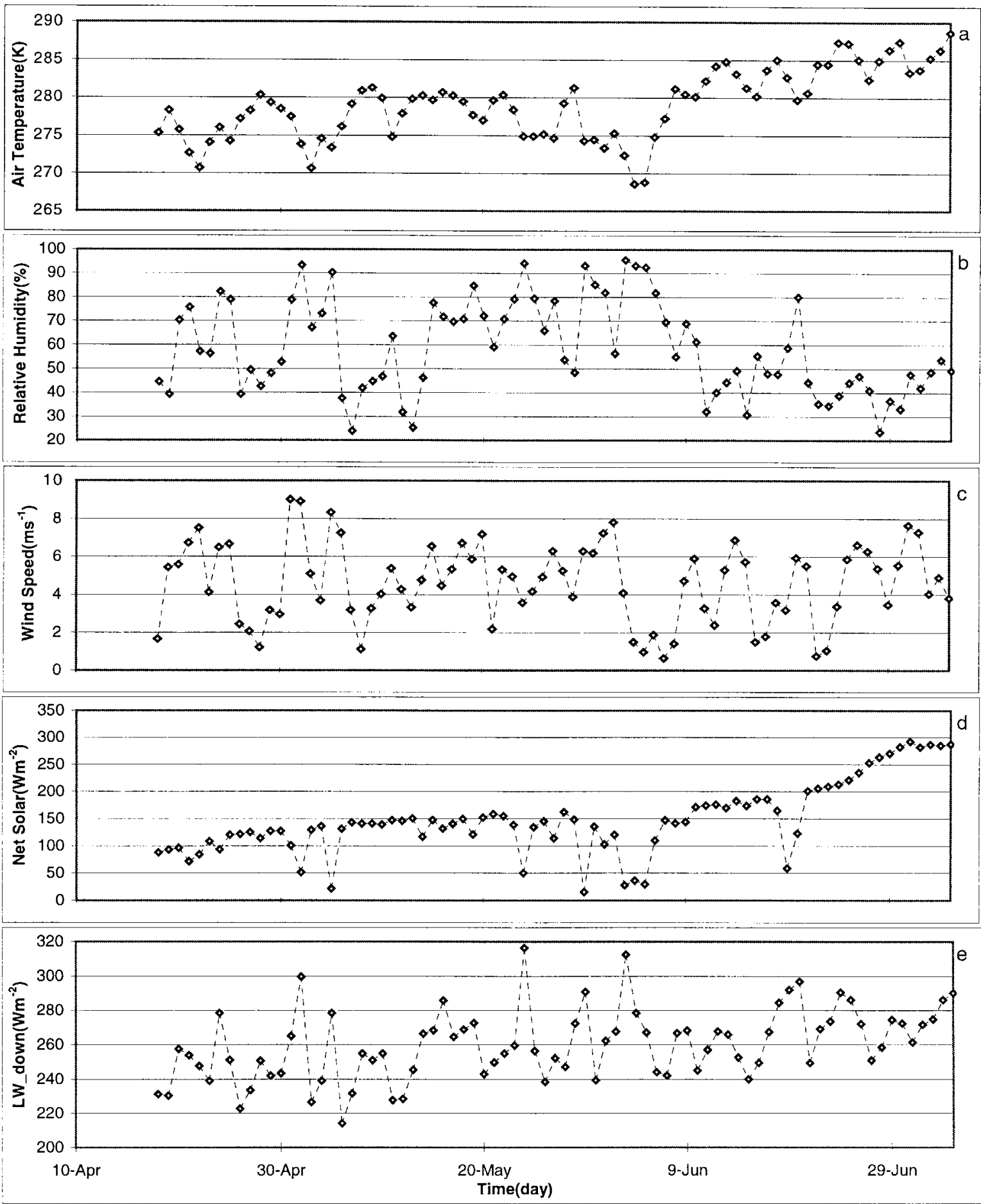

Figure 2. Time series of meteorological measurements from the Mammoth Mountain site for 1993. The north and south sites share the same meteorological data 


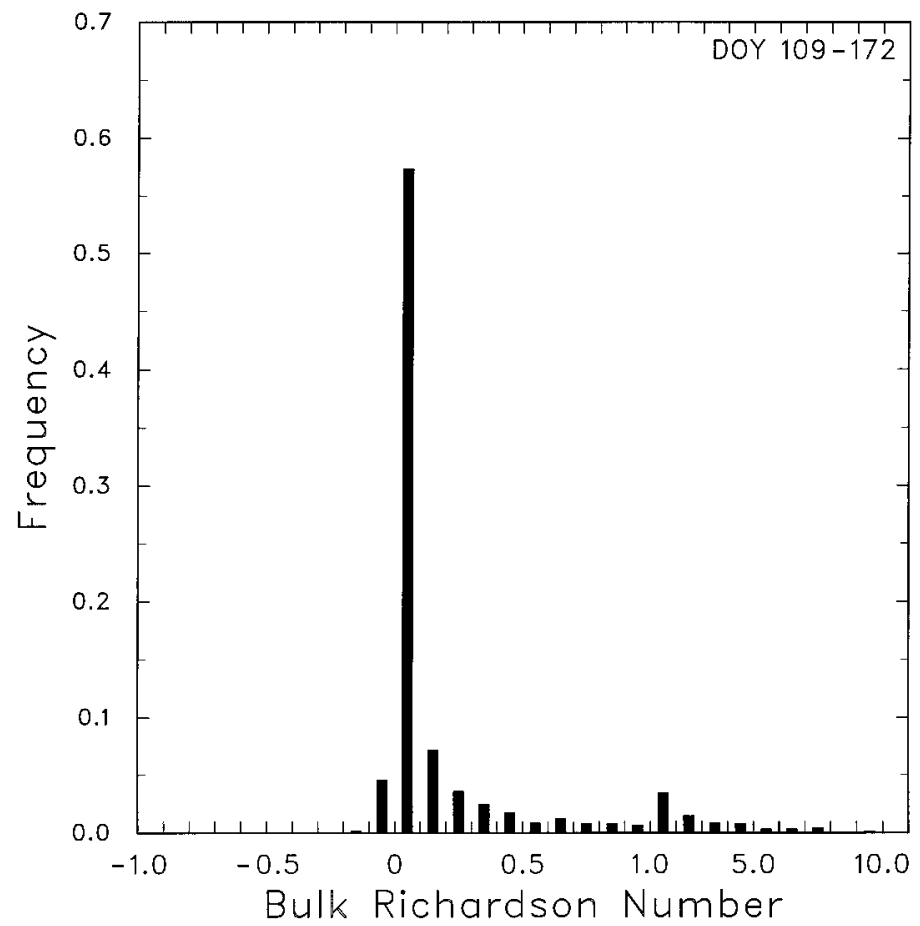

Figure 3. Histogram of bulk Richardson numbers $\left(R_{b}\right)$ using data from the north site at Mammoth Mountain, California for DOY 109-172, 1993. $R_{b}=g\left(z_{1}-d_{s}\right)\left(T_{1}-T_{s}\right) /\left[0 \cdot 5\left(T_{1}+T_{s}\right] V_{1}^{2}\right]$, where $g$ is acceleration of gravity, $z_{1}$ measurement height above soil surface $(=6.5 \mathrm{~m}), d_{s}$ snow depth above soil surface (simulated by SNTHERM but the modelled depth agrees with the observations), $T_{1}$ temperature measured at $z_{1}, T_{s}$ snow surface temperature (simulated by SNTHERM because of no measurement), $V_{1}$ wind velocity measured at $z_{1}$. Small fractions of $R_{b}<-1$ and $R_{b} \geqslant 10$ are not shown in the figure

neutral $C_{D}$, SNTHERM subtracts snow depth, which is up to three metres for the north site in the beginning of the melting season, from the instrument height $\left(z_{1}=6.5 \mathrm{~m}\right)$, while BATS does not make this adjustment. The SNTHERM adjustment enhances the neutral drag coefficient. However, it should be pointed out that in the version of BATS that is coupled to the NCAR CCM2 or CCM3, the von Karman constant is set to $0 \cdot 4$, and the snow roughness length is assumed to be $0.04 \mathrm{~m}$, both of which increase the neutral drag coefficients.

The other feature to note in Figure 4 is that the melting energy is primarily from the sensible heat flux and secondarily from the net radiation. Kuusisto (1986) provides examples of the relative importance of sensible versus net radiation in controlling melt for a wide range of environments. For open fields in mountains, sensible heat generally tends to be the dominant source in controlling melt. Other examples can be found in Gray and Prowse (1993). Neumann and Marsh (1998) discuss the role of local advection of sensible heat under patchy snowcover conditions.

Figure 6 compares the simulations of SWE, sublimation, sensible heat flux and snowmelt for a southern site from BATS and SNTHERM, both using the SNTHERM type of $C_{D}$ and observed albedo. BATS reproduces the observed SWE well, comparable to the more complex model. The loss of snow due to sublimation is negligible, the contribution from sensible heat flux to the snow melting is dominant over the net radiation, and the accumulated snowmelt curve nearly mirrors the SWE curve.

In the BATS design, no attention was paid specifically to the spring melt season, where daytime solar heating goes into the melting of snow rather than raising its temperature, and nighttime cooling can go into refreezing of the melted snow, a process ignored in the BATS design. This process can delay the release of meltwater (and therefore the decrease in SWE) for many days or weeks after the start of melt. In addition, BATS neglects flow fingers which can, in some cases, rapidly move meltwater through the snowpack before 

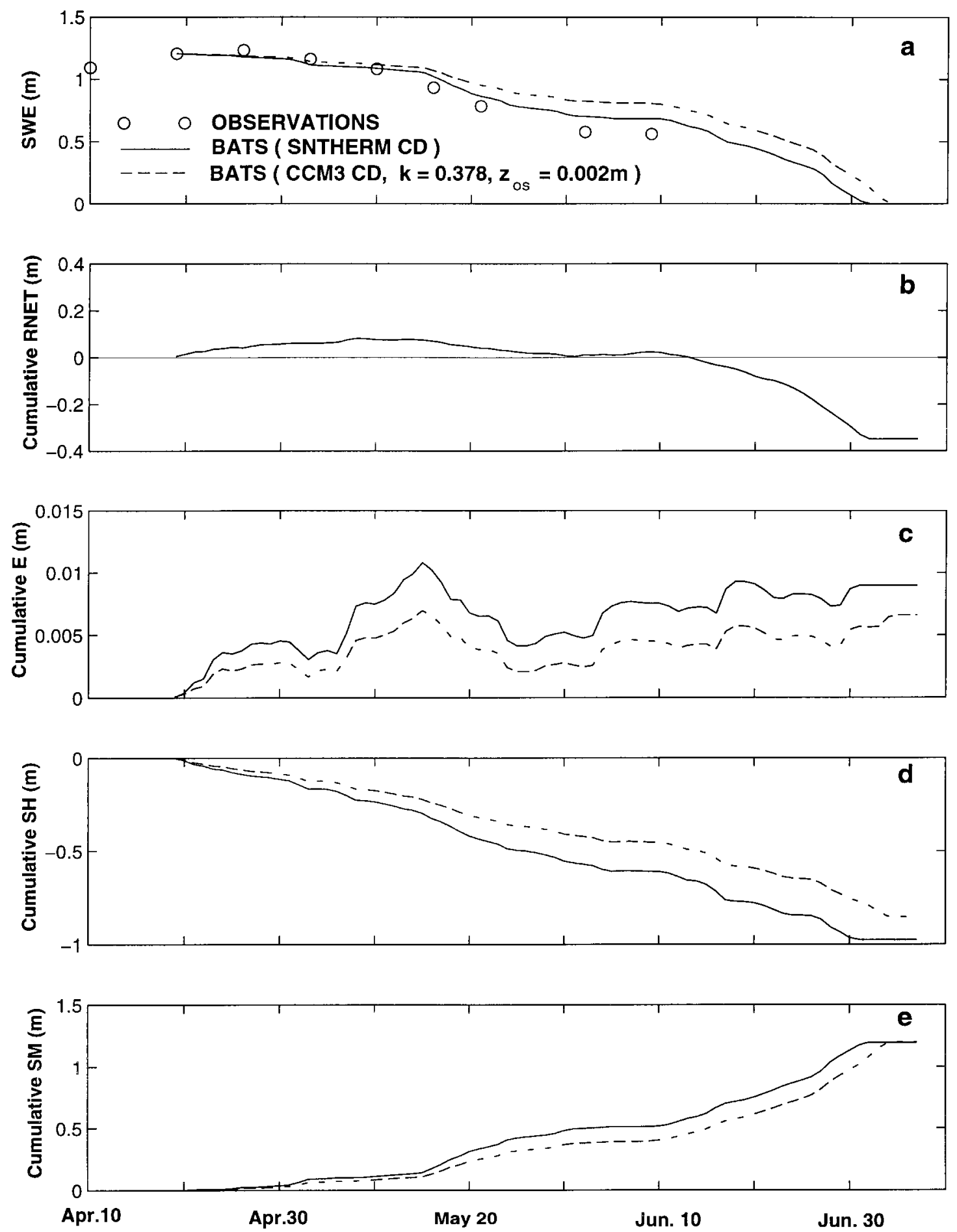

Figure 4. Time series of (a) snow water equivalent, (b) accumulated net radiation (RNET) in water equivalent, (c) accumulated sublimation, (d) accumulated sensible heat flux ( $\mathrm{SH})$ in water equivalent, and (e) accumulated snowmelt (SM) for the Mammoth Mountain north site for 1993. All simulations are performed with BATS. Both RNET and SH are divided by latent heat of fusion to convert to water equivalent for direct comparison with SM 


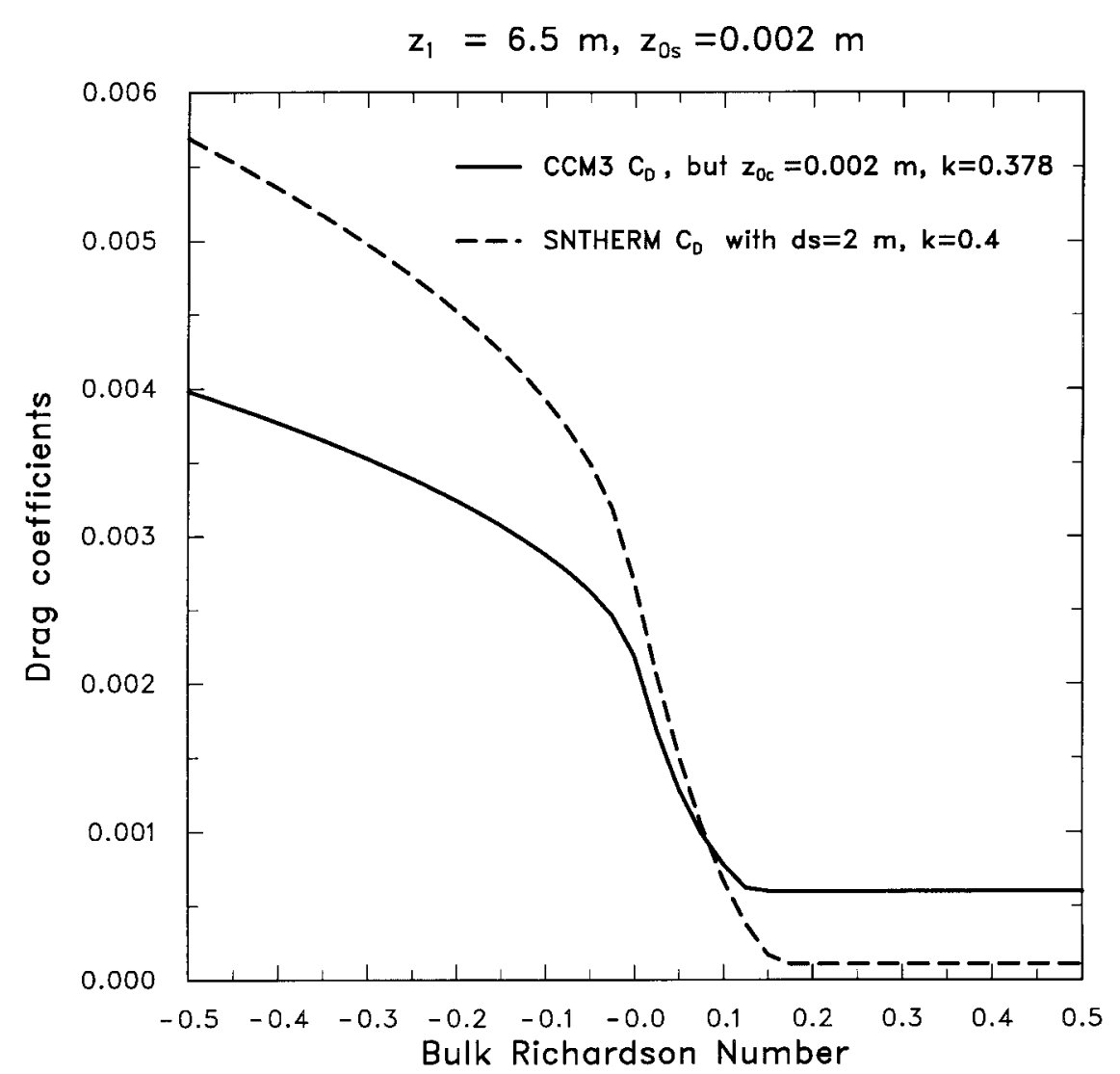

Figure 5. Drag coefficients as a function of bulk Richardson numbers $R_{b}$. The BATS drag coefficients (see equations (5) and (6) of Yang and Dickinson, 1996) are consistent with those used in CCM2 (Hack et al., 1993) or CCM3 (Kiehl et al., 1996). The SNTHERM drag coefficients are from equations (19)-(21) of Jordan (1992). In both formulations, $z_{1}=6.5 \mathrm{~m}$, and the roughness length for snow, $z_{0 s}=0.002 \mathrm{~m}$. However, von Karman constant $k$ is assumed to be 0.378 in BATS, and 0.4 in SNTHERM. SNTHERM also subtracts snow depth $d_{s}$ from $z_{1}$ in computing the neutral $C_{D} ; d_{s}$ is assumed to be $2 \mathrm{~m}$ for illustrative purpose in this figure only

the entire pack is wet and isothermal at $0{ }^{\circ} \mathrm{C}$. Our data fields were measured at an interval of ten days or longer, which is not sufficient to account for these features on this temporal scale. Our results indicate that beyond this scale, BATS can capture features such as ablation of a deep snowpack, its accumulated sublimation and meltwater outflow.

\section{SNOW COVER SIMULATIONS IN A GCM}

The GCM used in this study is version 3 of the Community Climate Model (CCM3) developed by NCAR (Kiehl et al., 1996). It has 18 vertical atmospheric levels extending from the surface boundary layer to the $2.9 \mathrm{mb}$ level, and a horizontal grid of approximately $2 \cdot 8^{\circ}$ by $2 \cdot 8^{\circ}$. CCM3 coupled with BATS (hereafter BATS-CCM3) was integrated for 12 years using climatological sea surface temperature. The initial soil moisture contents were taken from an archive of existing long simulations, which minimize the impacts of soil moisture initialization on the results. The first two years of integration were discarded, while the remaining years were averaged and used in analysis.

Figures 7 and 8 show a comparison of the model results (snow coverage, snow mass, precipitation and air temperature) with the observed data or estimates for North America $\left(0-90^{\circ} \mathrm{N}, 10-170^{\circ} \mathrm{W}\right.$, excluding Greenland) and Eurasia $\left(0-90^{\circ} \mathrm{N}, 10-170^{\circ} \mathrm{E}\right)$, respectively. Monthly observed snow coverage was derived 

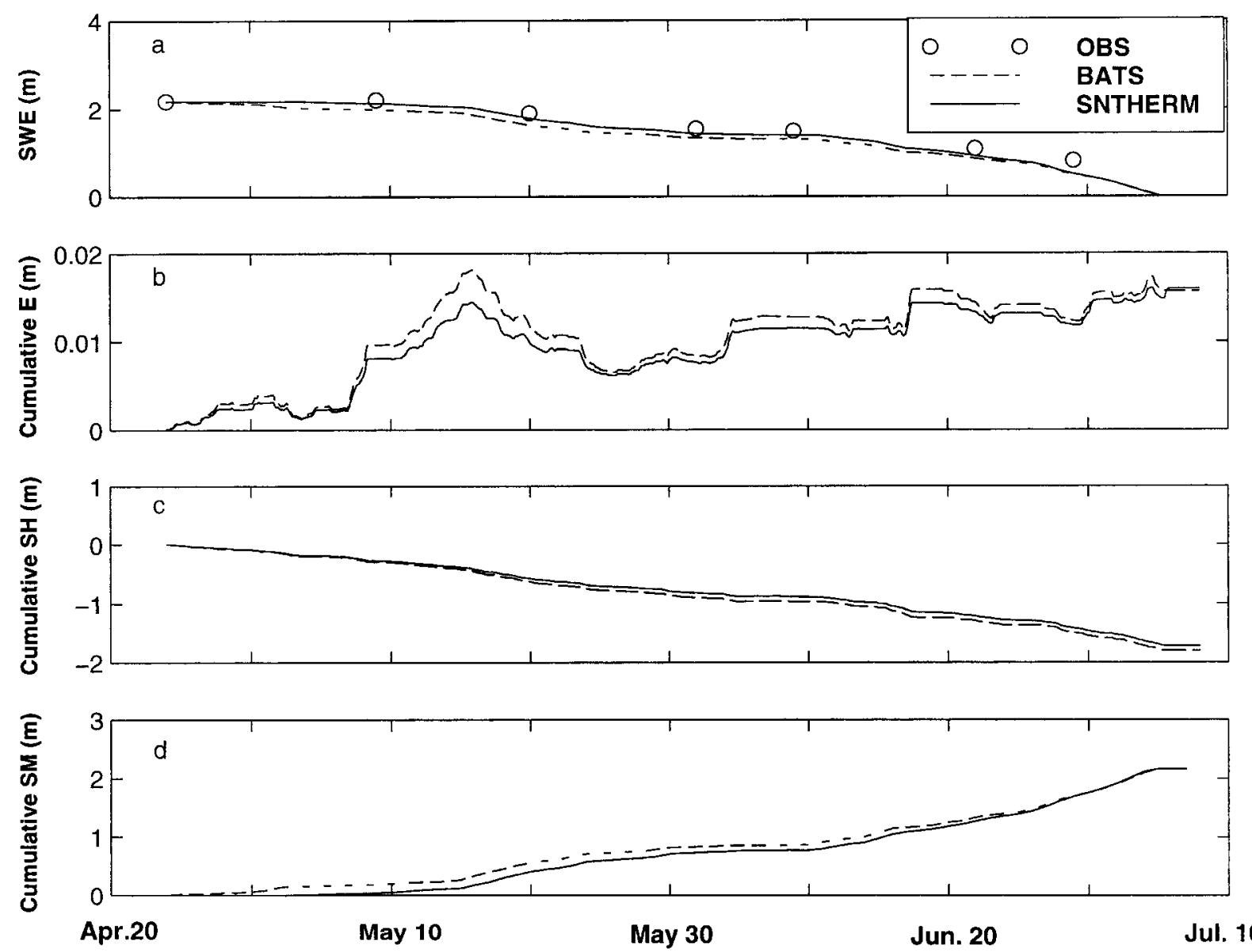

Figure 6. Time series of (a) snow water equivalent, (b) accumulated sublimation, (c) accumulated sensible heat flux (SH) in water equivalent, and (d) accumulated snowmelt (SM) for the Mammoth Mountain south site for 1993. All the simulations use the SNTHERM-type drag coefficients and observed albedo. SH is divided by the latent heat of fusion to convert to the water equivalent for a direct comparison with SM

from satellite imagery of snow extent as averaged over 1972-92 (Robinson et al., 1993). This imagery dataset was originally in weekly charts produced by trained meteorologists of the National Oceanic and Atmospheric Administration (NOAA) based on visual interpretation of photographic copies of visible satellite images. The snow mass data were originally compiled by the US Air Force Environmental Technical Applications Center (USAF/ETAC) at Scott Air Force Base in Illinois (Foster and Davy, 1988). The values shown in Figures 7 and 8 are based on those reported by Foster et al. (1996) because the gridded dataset was not available to us at the time of writing. Shown in Figures $7(a-b)$ and $8(a-b)$ are also passive microwave snow data (averaged for a period from 1978 through 1987) derived from the Nimbus-7 Scanning Multichannel Microwave Radiometer (SMMR) (Chang et al., 1987; Chang et al., 1992). Following Foster et al. (1996), the NOAA data are used as the standard of reference for snow extent observations and the USAF/ETAC data are used as the standard for snow mass. The precipitation and air temperature data are from Legates and Willmott (1990a,b).

Although the modelled snow cover extent was not saved in the output of the long integrations, it can be estimated using the approach described by Frei and Robinson (1998). A grid square is considered to be completely snow covered if the snow depth is $\geqslant 3 \mathrm{~cm}$. If the snow depth is $<3 \mathrm{~cm}$, the fractional coverage is 

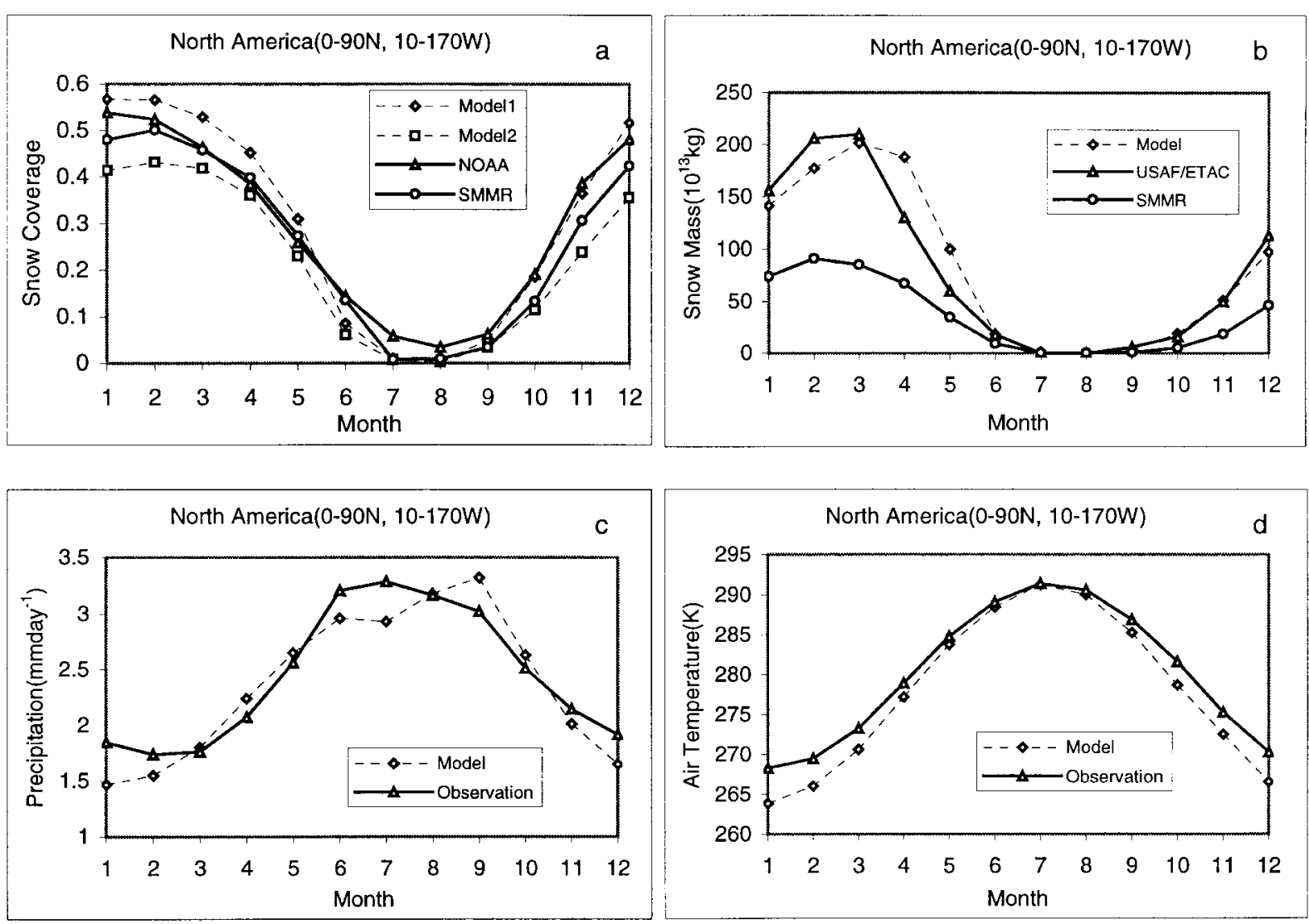

Figure 7. Annual cycle of (a) snow cover extent, (b) snow mass, (c) precipitation and (d) air temperature for North America. In (a), 'NOAA' refers to the NOAA satellite data (Robinson et al., 1993); 'SMMR' refers to the passive microwave data (Chang et al., 1987; Chang et al., 1992). Both 'Model 1' and 'Model 2' are described in the text. In (b) 'USAF/ETAC' refers to the data from Foster and Davy (1988). 'Observation' refers to Legates and Willmott (1990a) in (c) and Legates and Willmott (1990b) in (d)

computed as a ratio of snow depth to a value of $3 \mathrm{~cm}$. Because snow density is not saved either, the snow depth is estimated from the snow water equivalent assuming the snow density is equal to $300 \mathrm{~kg} \mathrm{~m}^{-3}$, a value used by Foster et al. (1996) and Frei and Robinson (1998). The snow cover extent calculated this way is shown in Figure 7 as 'Model 1' in comparison with the NOAA data. The choice of $3 \mathrm{~cm}$ is consistent with the NOAA practice (Frei and Robinson, 1998). The SMMR snow depth data are processed in the same manner as 'Model 1' and are also shown in Figures 7(a) and 8(a). This simple method should be used with caution as it might not be appropriate for any environment with moderately rugged terrain, or where blowing snow is important. In these cases spatial variations in SWE are very large and, especially during the melt period, this simple approach is expected to give error, as indicated in Figure 7. However, this method provides a good fit to observational estimates during the accumulation period for both North America and Eurasia. In comparison, 'Model 2', which computes the snow cover extent as a ratio of snow depth to the sum of snow depth and ten times soil surface roughness length $(1 \mathrm{~cm})$, is also shown in Figures 7 and 8 . The density used to convert snow mass to depth is $300 \mathrm{~kg} \mathrm{~m}^{-3}$. This approach is more realistic than 'Model 1' during the melt period, but is worse during the accumulation period.

In terms of continents, the snow mass is better simulated during the accumulation period than during the melt period for both North America and Eurasia. The model tends to lag by one month to reach the peak snow mass and the onset of melt is delayed accordingly. However, the simulations for North America are 

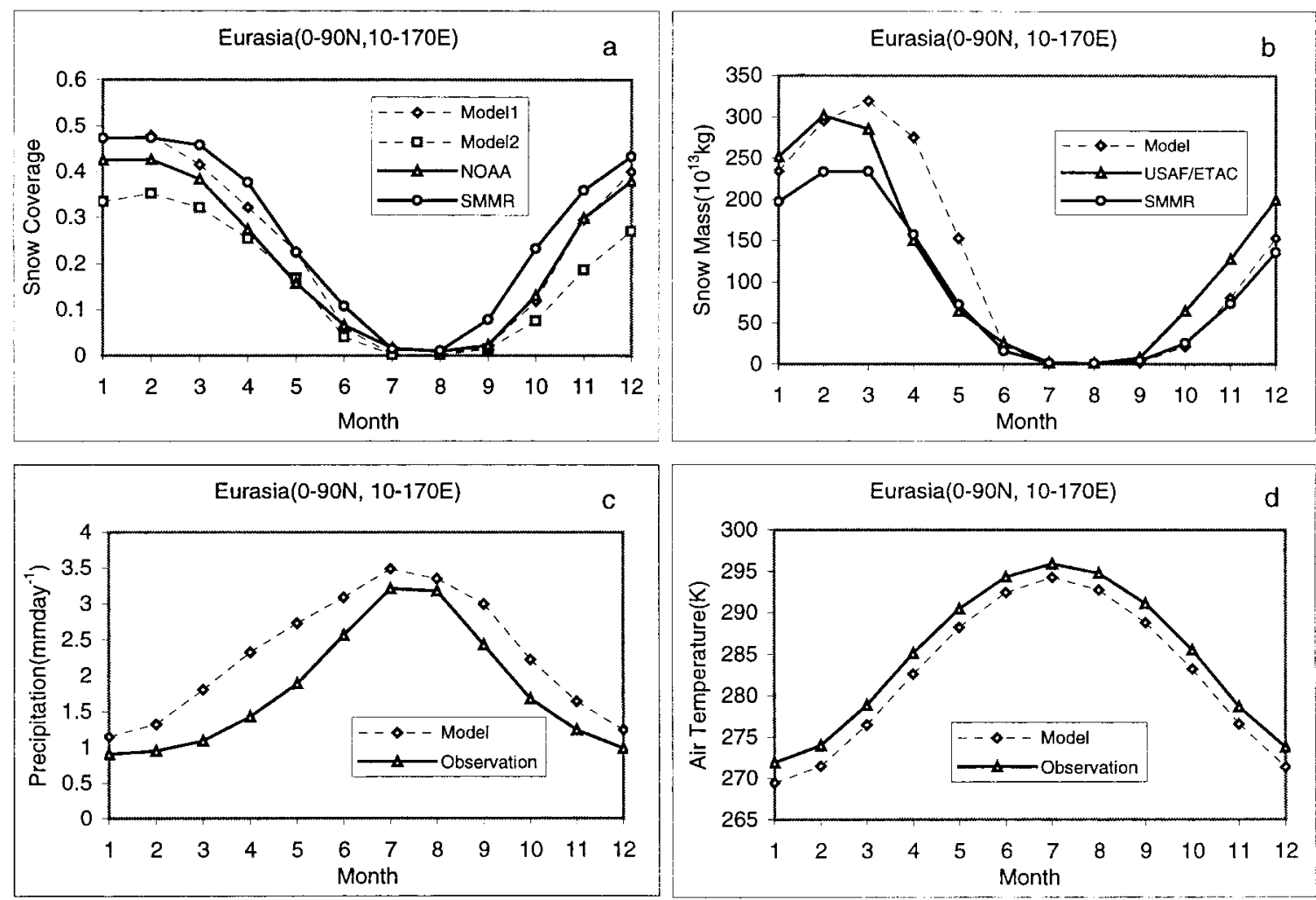

Figure 8. As Figure 7, but for Eurasia

slightly better than those for Eurasia. Overall, the snow mass simulations presented here from BATS-CCM3 compare more favourably with observations than those from most of the coupled models in Foster et al. (1996) who compared seven GCMs with observations. The snow cover from SMMR generally underestimates the NOAA data for North America but overestimates the NOAA data for Eurasia, although these two sets of data have better agreement for North America, especially from February to June. This statement differs from that in Foster et al. (1996), presumably due to the different values of threshold used for the minimum snow depth to cover the surface. In our derivations, we used $3 \mathrm{~cm}$ for the threshold but assumed a fractional cover for snow depth $<3 \mathrm{~cm}$. If we neglected this fractional cover, then the SMMR estimates would be closer to the NOAA data for Eurasia than for North America. However, the SMMR-derived snow mass significantly underestimates the USAF/ETAC data for North America, while these two sets of data show much better agreement for Eurasia. Consequently, for North America, the BATS-CCM3 results agree better with the USAF/ETAC data throughout the snow season than the SMMR estimates do, while for Eurasia, the SMMR data are in better agreement with the USAF/ETAC data than the BATS-CCM3 simulations during the late ablation season (April and May).

Figures 7 and 8 show that, relative to Eurasia, the more accurate simulations of snow mass in North America from BATS-CCM3 correlate well with the more accurate simulations of precipitation and air temperature for this continent. These differences are partially related to the size of the mountainous regions in these two continents. BATS-CCM3 has a cold and wet bias over these mountain ranges. This bias is even greater in Eurasia than in North America because the former has more extensive mountain ranges than the latter.

Figures 9 and 10 show the geographic distribution of snow depth for individual months (November through April) from BATS-CCM3 and SMMR for North America and Eurasia, respectively. The 

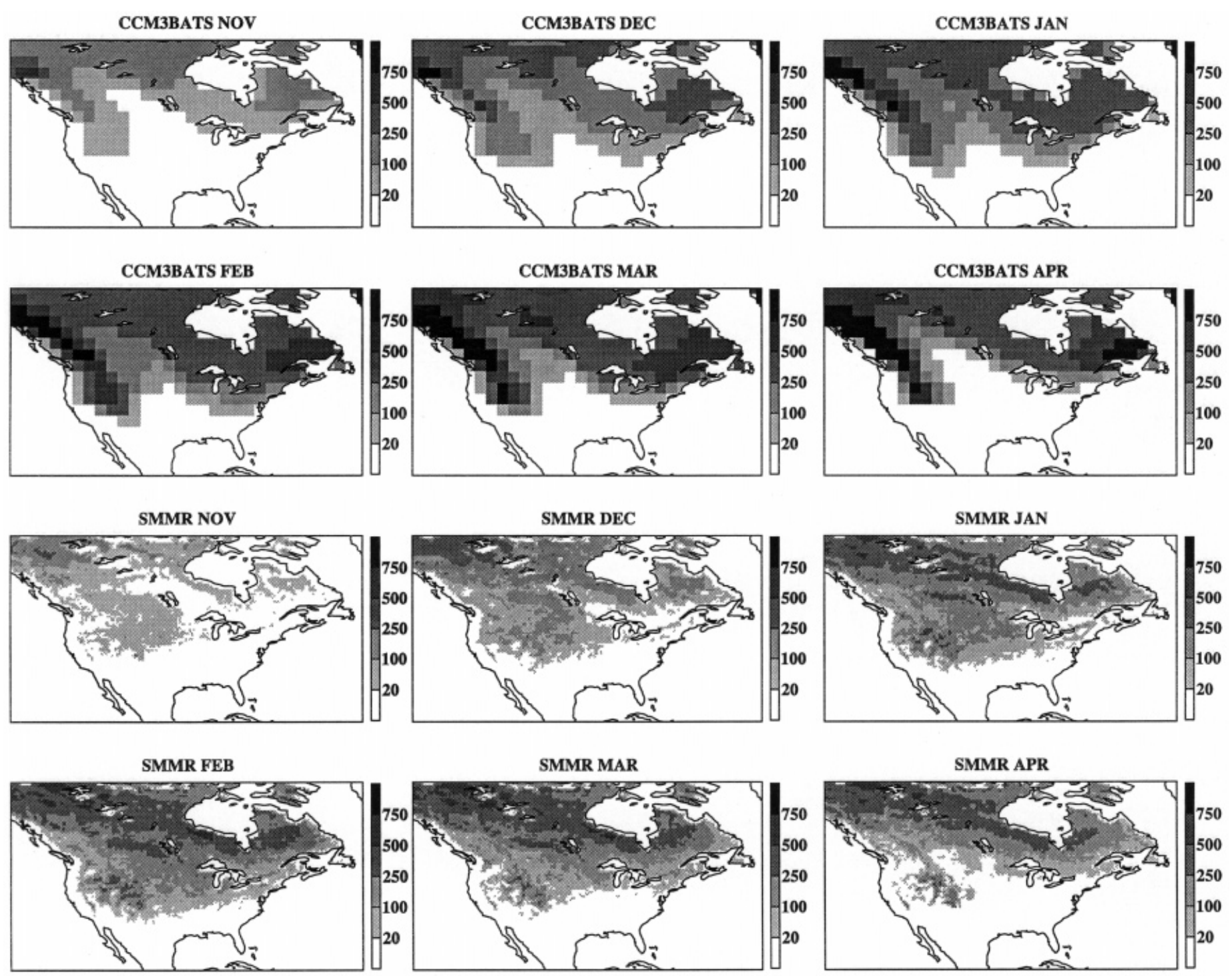

Figure 9. Comparison of monthly snow depth $(\mathrm{mm})$ over the North America (here indicating USA and Canada) regions from BATS-CCM3 and SMMR 

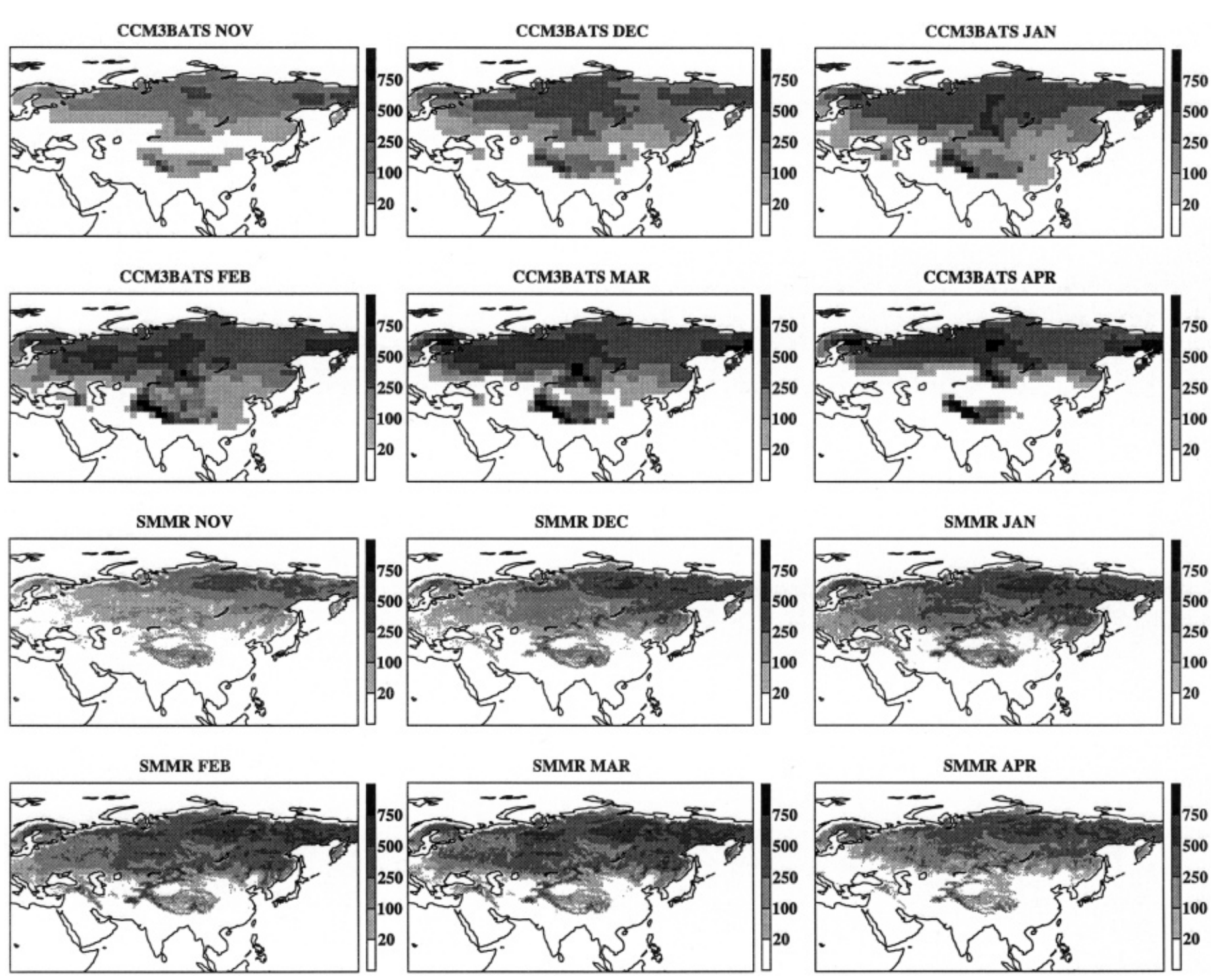

Figure 10. As Figure 9, but for Eurasia 
SMMR estimates are used here because they are available at high spatial resolution $\left(0 \cdot 5^{\circ}\right)$ and provide a spatially-continuous field to be compared with the modelled results. Compared with other data products such as NOAA and USAF/ETAC, the SMMR data are good for uniform snow covered areas such as the Canadian high plains and Russian steppes. The microwave algorithms currently in use tend to underestimate snow depth (see Figures 7(b) and 8(b)), particularly in the regions of shallow and melting snow, and heavily forested and mountainous areas (Chang et al., 1987; Foster et al., 1996). The most apparent differences between modelled snow depth and SMMR data for North America are located in the Rocky Mountains, south of Hudson Bay, Southeastern Canada, Northeastern United States, and the Great Lakes regions. For Eurasia, the differences between the modelled and the SMMR data are noticeable mainly in Scandinavia, the northern Urals, central and eastern Siberia. Generally, modelled values are greater than those from SMMR. Foster et al. (1996) show that over these regions the SMMR data underestimate snow mass, suggesting that our results, in general, compare more favourably with observations.

The results presented in this paper and elsewhere (e.g., Foster et al., 1996; Frei and Robinson, 1998) indicate a need for future GCM integrations to report snow depth or density in addition to snow water equivalent. This would avoid the possible inaccuracies in estimating depth using a fixed snow density. To better match the satellite product of snow cover extent, the snow cover fraction that is used in computing snow patch surface albedo should be saved in the GCM runs if this variable is computed in the models. For a detailed analysis of the snow energy and water budget, additional variables related to snow are also needed as output, such as snowfall, sublimation, snowmelt, sensible heat flux, absorbed solar radiation and net radiation. From a practical point of data storage, only time-averaged variables (at monthly intervals) are saved.

\section{DISCUSSION}

Because of the importance of snow for accurate climate simulations, what level of complexity of snow modelling is adequate for GCMs must be determined and how the accuracy of snow models is related to the consideration or omission of snow internal processes must be addressed. The BATS snow model neglects retention of meltwater in the snowpack, which may be a reasonable assumption in temperate snow covers, as in this study, but not for Arctic areas (see Marsh, 1991). The BATS canopy model neglects the penetration of solar radiation through the canopy, which may affect the timing of snowmelt in the forest regions. Therefore, the model needs to be tested with field data for a wide range of environments as listed in Table I (Kuusisto, 1986) if these data are available.

Several features of process-level snowmelt models could be used to help capture the sub-grid scale variability and improve snowmelt simulations. An active line of research is being established to link the physically based snowmelt models, geographical information system (GIS) analysis, remote sensing technology and assimilated datasets from mesoscale meteorological models for studies in small catchments and watersheds. However, relatively speaking, what is lacking is research and the application of snow water and energy budget analyses at continental or global scales. A question that remains unresolved is the level of complexity required for snow models on those scales. A closely related question is how to relate a snowpack model (one-dimensional in the vertical direction) to the heterogeneous surfaces in each of the GCM land grids. Specifically, what is the optimum methodology to derive a grid effective value of albedo, roughness length and wetness factor when snow patchiness is present? The heterogeneous distribution of vegetation and topography adds more complexity to this problem. Nevertheless, conclusions drawn from research at subresolution scales (e.g. local, catchment and watershed scales) will provide an important guide towards developing and improving snow process models at GCM scales.

\section{CONCLUSIONS}

For local scales in the stand alone mode, the BATS snow model has been evaluated with two datasets: the Russian midlatitude grassland sites and the California Alpine site. These tests show that the BATS snow 
model can realistically simulate surface snow processes on a temporal scale of ten days or longer. These results are consistent with the findings in Schlosser et al. (1999) which compare more than 20 snow models (including BATS) using the data from Valdai, Russia.

On continental scales in the coupled land-atmosphere model, BATS-CCM3 can simulate both snow cover and snow mass quite well. For both North America and Eurasia, the snow mass is simulated more accurately during the accumulation period than during the melt period. The simulations of snow mass, precipitation and air temperature for North America are slightly better than those for Eurasia.

A rigorous evaluation of snow simulations in coupled land-atmosphere models requires high quality global datasets of snow cover extent, snow depth and snow water equivalent. It also requires the models to save the same set of variables plus snowmelt, sublimation, snowfall, snow temperature, and other snow-related energy and water fluxes to provide a direct match to the observed fields and for in-depth understanding of snow processes. The available datasets and model outputs are not yet ready to fulfil this objective.

A comprehensive snow model survey with 50 questions has been distributed summarizing the status of snow models used in various applications, and more than 40 responses have been received to date. These questions and responses have been documented on the World Wide Web (www.atmo.arizona.edu/ zly/ snow.html). An initial analysis of these responses indicates that there are a number of sophisticated snow models available at the point or local scale, and there is a wide range of models developed for application in small catchments and watersheds.

The preliminary analysis from a recent survey of snow model components indicates that the future lines of research in climate snow modelling are: (1) development of an optimum snowpack model which not only simulates the snow processes but also captures the soil temperature variations under the snowpack; (2) linkage of this model to heterogeneous vegetation and topography distribution; (3) use of remotely sensed data to derive vegetation and snow parameters and for model validation.

\section{ACKNOWLEDGEMENTS}

The authors wish to thank Dr Philip Marsh for constructive comments. The research described in this paper was carried out under NASA EOS Interdisciplinary Scientific Research Program (U.P.N. 428-81-22 and U.P.N. 429-81-22) and a NASA Grant NAG8-1520. XG and SS were supported under NASA/EOS Interdisciplinary Research Program NAG53640\#1. RCB acknowledges support from EOS grant NAGW-2062. JJ would like to thank the World Laboratory, International Centre for Scientific Culture (Switzerland) for selecting him as the first recipient of the John Harshbarger Fellowship.

\section{REFERENCES}

Anderson EA. 1976. A Point Energy and Mass Balance Model of a Snow Cover. Office of Hydrology, National Weather Service. Cess RD, and 32 Co-authors. 1991. Intercomparison of snow-feedback as produced by general circulation models. Science 253: $888-892$.

Chang ATC, Foster JL, Hall DK. 1987. Nimbus-7 SMMR derived global snow cover parameters. Annals of Glaciology 9: 39-44.

Chang ATC, Foster JL, Hall DK, Powell HW, Chien YL. 1992. Nimbus-7 SMMR derived global snow cover and snow depth data set. The Pilot Land Data System, NASA/Goddard Space Flight Center: Greenbelt, MD.

Dickinson RE. 1988. The force-restore model for surface temperatures and its generalizations. Journal of Climate 1: $1086-1097$.

Dickinson RE, Jager J, Washington WM, Wolski R. 1981. Boundary subroutine for the NCAR global climate model. NCAR Technical Note, NCAR/TN-173 + IA.

Dickinson RE, Henderson-Sellers A, Kennedy PJ, Wilson MF. 1986. Biosphere Atmosphere Transfer Scheme (BATS) for the NCAR Community Climate Model. NCAR Technical Note, NCAR/TN-275 + STR.

Dickinson RE, Henderson-Sellers A, Kennedy PJ. 1993. Biosphere Atmosphere Transfer Scheme (BATS) version 1e as coupled to the NCAR Community Climate Model. NCAR Technical Note, NCAR/TN-387 + STR.

Foster DJ Jr, Davy RD. 1988. Global snow depth climatology. USAF publication USAFETAC/TN-88/006, Scott Air Force Base, Illinois.

Foster J, Liston G, Koster R, Essery R, Behr H, Dumenil L, Verseghy D, Thompson S, Pollard D, Cohen J. 1996. Snow cover and snow mass intercomparisons of general circulation models and remotely sensed datasets. Journal of Climate 9: 409-426. 
Frei A, Robinson DA. 1998. Evaluation of snow extent and its variability in the atmospheric model intercomparison project. Journal of Geophysical Research 103: 8859-8871.

Gray DM, Prowse TD. 1993. Snow and floating ice. In Handbook of Hydrology, Maidment DR (ed.). McGraw-Hill, Inc., New York: pp. 7.1-7.58.

Hack JJ, Boville BA, Briegleb BP, Kiehl JT, Rasch PJ, Williamson DL. 1993. Description of the NCAR Community Climate Model (CCM2). NCAR Technical Note, NCAR/TN-382 + STR.

Harrington RF, Bales RC. 1998. Interannual, seasonal and spatial patterns of meltwater and solute fluxes in a seasonal snowpack. Water Resources Research 34: 823-831.

Holtslag AAM, Boville BA. 1993. Local versus nonlocal boundary-layer diffusion in a global climate model. Journal of Climate 6: $1825-1842$.

Jin JM, Gao X, Yang Z-L, Bales RC, Sorooshian S, Dickinson RE, Sun S, Wu G. 1999. Comparative analyses of physically based snowmelt models for coupled atmospheric models. Journal of Climate, (in press).

Jordan R. 1991. A one-dimensional temperature model for a snow cover. US Army Corps of Engineers, Cold Regions Research and Engineering Laboratory, Special Report 91-16.

Jordan R. 1992. Estimating Turbulent Transfer Functions for use in Energy Balance Models. US Army Corps of Engineers, Cold Regions Research and Engineering Laboratory, Internal Report 1107.

Kiehl JT, Hack JJ, Bonan GB, Boville BA, Briegleb BP, Williamson DL, Rasch PJ. 1996. Description of the NCAR Community Climate Model (CCM3). NCAR Technical Note, NCAR/TN-420 + STR

Kuusisto E. 1986. The energy balance of a melting snow cover in different environments. IAHS Publication 155: 37-45.

Legates DR, Willmott CJ. 1990a. Mean seasonal and spatial variability in gage-corrected, global precipitation. International Journal of Climatology 10: 111-127.

Legates DR, Willmott CJ. 1990b. Mean seasonal and spatial variability in global surface air temperature. Theoretical and Applied Climatology 41: 11-21.

Loth B, Graf H-F, Oberhuber JM. 1993. Snow cover model for global climate simulations. Journal of Geophysical Research 98 : $10451-10464$.

Lynch-Stieglitz M. 1994. The development and validation of a simple snow model for the GISS GCM. Journal of Climate 7: $1842-1855$.

Marsh P. 1991. Water flux in melting snow covers. In Advances in Porous Media Corapcioglu MY. (ed.), Elsevier, Amsterdam: pp. 61-124.

Marshall S, Roads JO, Glatzmaier G. 1994. Snow hydrology in a general circulation model. Journal of Climate 7: 1251-1269.

Neumann N, Marsh P. 1998. Local advection of sensible heat in the snowmelt landscape of Arctic tundra. Hydrological Processes 12: $1547-1560$.

Robinson DA, Dewey KF, Heim RR Jr. 1993. Global snow cover monitoring: an update. Bulletin of the American Meteorological Society 74: 1689-1696.

Robock A, Vinnikov KYa, Schlosser CA, Speranskaya NA, Xue Y. 1995. Use of midlatitude soil moisture and meteorological observations to validate soil moisture simulations with biosphere and bucket models. Journal of Climate 8: 15-35.

Schlosser CA, and 31 co-authors. 1999. Simulations of a boreal grassland hydrology at Valdai, Russia: PILPS Phase 2(d). Monthly Weather Review, (in press).

Verseghy DL. 1991. CLASS - a Canadian Land Surface Scheme for GCMs. Part I: Soil Model. International Journal of Climatology 11: $111-133$.

Yang Z-L, Dickinson RE, Robock A, Vinnikov KYa. 1997. Validation of the snow sub-model of the Biosphere-Atmosphere Transfer Scheme with Russian snow cover and meteorological observational data. Journal of Climate 10: 353-373.

Yang Z-L, Dickinson RE, Henderson-Sellers A, Pitman AJ. 1995. Preliminary study of spin-up processes in land surface models with the first stage data of Project for Intercomparison of Land Surface Parameterization Schemes Phase 1(a). Journal of Geophysical Research 100: 16553-16578.

Yang Z-L, Dickinson RE. 1996. Description of the biosphere-atmosphere transfer scheme (BATS) for the Soil Moisture Workshop and evaluation of its performance. Global and Planetary Change 13: 117-134.

Yang Z-L, Dickinson RE, Shuttleworth WJ, Shaikh M. 1998. Treatment of soil, vegetation and snow in land-surface models: a test of the biosphere-atmosphere transfer scheme with the HAPEX-MOBILHY, ABRACOS, and Russian data. Journal of Hydrology 212-213: 109-127.

Yeh T-C, Wetherald RT, Manabe S. 1983. A model study of the short-term climate and hydrologic effects of sudden snow-cover removal. Monthly Weather Review 111: 1013-1024. 